\title{
Covid 19: The lessons
}

Bryan McIntosh, Associate Professor, York St John University, York, UK

Jennifer Bromley, Physiotherapy lecturer: practice education lead, University of Bradford, Bradford, UK

The country is at war. The enemy is unseen, invisible, hidden, it has no guns, it is relentless but there are many casualties. COVID-19, Coronavirus, for those with weakened immune systems it is a potential killer. At the time of writing it has caused thousands of deaths and so many are known to have contracted the disease. This is a $50 \%$ fatality rate in ICU in the UK.

The NHS have successfully so far managed to test thousands, setting up drive through test clinics, reducing in-patient appointments to telephone appointments to free up doctor time and maintain doctor's health for the sake of their patients. The NHS has engaged with commercial organisations and the military to create "new" hospital. Since the creation of the NHS, these achievements are unparalleled. The demand on society is not restricted to the virus, but the mental anxieties and illnesses that self-isolation brings. With solitude comes loneliness, claustrophobia and anxiety. Fear, the stockpiling of food has exacerbated this. All of this puts further strain on the NHS and the NHS will need more than is currently on hand and promised to it by the recent election and there are other serious implications.

The first concerns national security. The pandemic took the country by surprise, despite its drum beat being heard across the globe. We must invest in health like we do in security - that means rethinking national budgets to dedicate strategic resources to research, development and training in the medical sector and also to the purchase and production of materials destined to become crucial supplies in this country. We cannot be dependent on other countries vital medical products and services; we must be willing to bear that cost both financial and political. What this requires is the country to equip itself urgently with an effective, well-structured and even better funded biosecurity policy. The key to success in resisting pandemic attacks is in the logistics: the more hospitals, beds, specialists, nurses, machinery and medicines there are, the more our collective life is protected.

The second lesson is the crucial importance of collaboration between citizens and official institutions. If the government has locked down public life, forced millions of people into a de facto quarantine and faced economic costs that risk recession, it is because this is the only effective prescription to stem - and ultimately defeat - the virus. But for that to be successful, it is necessary for every individual citizen to play their part responsibly. In Western democracies, there is a constitutional limit to the obligations that can be imposed on citizens, hence the importance of personal responsibility. It is vital for everyone to understand the importance of the limitations they accept and to participate consciously in creating an enabling environment to support behaviour change. Fast, decisive political leadership is crucial. School closures and quarantine measures are powerful tools. But supporting safer behaviours means addressing structures that constrain or enable people's choices for example, the scarcity of clean water will limit handwashing.

There is also a third element: the mobilising of technology to support the NHS; Utilising manufacturing specialist from the defence, aerospace, nuclear, energy, medical and industrial sectors. It manufactures safety critical products which can be adapted rapidly. The capacity of the UK industrial, technology and engineering businesses from across the aerospace, automotive and medical sectors, can be integrated not just to be a reserve resource but a current and actual resource. 
There is a fourth challenge: Remodelling service delivery, particularly in primary care, where new emergent roles have occurred in the last several weeks. This remodelling has the potential to build on the high-quality care, enhanced independence and increased health autonomy, which have secured delivery process during the crisis. These maxims have come to the fore with the medical and health profession fulfilling the goals of the value-based agenda. It becomes more imperative to build on extended scope roles and invest in those staff to retain and build their existing workforce and commit to delivering on these changes (Bromley \& McIntosh, 2016).

There is a fifth element: Integrated big data. Different parts of the NHS already possess the data but staying ahead of any pandemic will require streamline the information is used. Creating a single the first operational model of a national Learning Health System in which there is a data-driven transformation of health policy and planning, service delivery and evaluation, provision is essential. With a single place to gather and analyse this data, decision-makers will be able to move as quickly as the response demands; data held by disparate organisations can be and will need to be synchronised with epidemiological models which can predict the dynamics of an epidemic. A multidisciplinary effort is essential to design, characterise, and evaluate interventions that can shape behaviour (MCINTOSH, 2016).

The United Kingdom is adapting to the emergency by ensuring that life prevails over fear of the virus, and by refuting the selfishness of people who are reluctant to respect laws and regulations: the truth is that when life is at stake, even the most foolish of citizens can becomes foot solider in the battle ahead. This is a sign of the energy of the NHS and our nation and the best guarantee of being able to raise ourselves up again when the coronavirus crisis is defeated. Even if the challenge is far from over. In many ways this is really only the end of the beginning, if we are to grow from this, these lessons must be built upon.

\section{References}

Bromley, J \& McIntosh, B (2016), "Change and opportunity: Challenges for service delivery in physiotherapy", International Journal of Therapy and Rehabilitation, 23 (12), 565-566

McIntosh, B (2016), "The need for a National Centre for Excellence in Clinical Imaging", British Journal of Healthcare Management, 22 (3), 110-111 